\title{
Docentreductie in de tutorgroep: wat vinden de studenten ervan?
}

\author{
M. Penninga, J. Schönrock-Adema, J. Cohen-Schotanus
}

\section{Samenvatting}

Inleiding: Bij de studie Geneeskunde aan de Rijksuniversiteit Groningen komen studenten twee keer per week in tutorgroepen bijeen. Tijdens de eerste bijeenkomst van de week wordt gebrainstormd over studieopdrachten. Deze worden vervolgens uitgewerkt en in de tweede bijeenkomst gepresenteerd. Om docentinzet te verminderen, werd ervoor gekozen één bijeenkomst zonder tutorbegeleiding te laten plaatsvinden. Studenten hebben in twee opeenvolgende trimesters de eerste respectievelijk de tweede bijeenkomst zonder begeleiding uitgevoerd. In dit onderzoek wordt op reactieniveau nagegaan welke situatie de voorkeur van studenten had.

Methode: Het onderzoek werd uitgevoerd onder 272 derdejaars studenten, die tijdens het eerste trimester de eerste en tijdens het tweede trimester de tweede bijeenkomst zonder begeleiding uitvoerden. In totaal hebben 241 studenten (88.6\%) een vragenlijst ingevuld. Deze vragenlijst bestaat uit 20 vragen, die op een 3-puntsschaal dienen te worden beantwoord. Hierbij wordt studenten gevraagd beide begeleidingsvormen met elkaar te vergelijken.

Resultaten: De helft van de studenten prefereerde een tweede en $40 \%$ een eerste bijeenkomst met begeleiding. Bijna $40 \%$ van de studenten vindt de kwaliteit van de brainstormsessie minder als deze zonder begeleiding plaatsvindt. De kwaliteit van de presentaties is volgens $48.3 \%$ van de studenten in beide situaties hetzelfde en $35 \%$ vindt de kwaliteit lager in de situatie waarin de presentaties zonder begeleiding plaatsvonden.

Discussie en conclusies: De belangrijkste bevinding is dat een groot deel van de studenten van mening is dat onderdelen die zonder begeleiding plaatsvonden slechter werden uitgevoerd. Het verdient aanbeveling in vervolgonderzoek na te gaan wat de invloed van docentreductie is op leereffecten. (Penninga M, Schönrock-Adema J, Cohen-Schotanus J. Docentreductie in de tutorgroep: wat vinden de studenten ervan? Tijdschrift voor Medisch Onderwijs 2004;23(5):211-219.)

\section{Inleiding}

Probleemgestuurd onderwijs (PGO) is een vorm van studentgecentreerd onderwijs waarin een sterke nadruk ligt op actief leren. Centraal staat hoe de student zelf kennis verwerft en niet zozeer hoe de docent kennis overbrengt. PGO moet er toe leiden dat studenten efficiënt kennis opnemen en gebruiken door het zelf op te zoeken, kritisch te verwerken en terug te kijken op hoe ze dit hebben gedaan (zelfreflectie). ${ }^{1}$

Om dit te kunnen bereiken, vindt een groot gedeelte van het onderwijs aan de
Faculteit der Medische Wetenschappen van de Rijksuniversiteit Groningen (FMW/ RUG) plaats in tutorgroepen. Deze tutorgroepen bestaan uit ongeveer tien studenten die per week twee keer bij elkaar komen. Het doel van de tutorgroepbijeenkomsten is dat studenten actief met de leerstof bezig zijn en patiënt- dan wel probleemgericht leren denken. Daarnaast leren zij samenwerken in een groep, discussiëren en mondeling presenteren.

In de eerste bijeenkomst van de week vindt een brainstormsessie plaats over vier studieopdrachten. Naar aanleiding 
van de brainstormsessie worden, per studieopdracht, verschillende vragen geformuleerd die verder uitgezocht dienen te worden. Deze uitwerking wordt in de tweede bijeenkomst van de week gepresenteerd. Vragen die onbeantwoord zijn gebleven of naar aanleiding van de presentaties naar voren zijn gekomen, kunnen worden gesteld in het responsiecollege dat aan het eind van de betreffende week plaatsvindt.

De studenten vervullen verschillende rollen tijdens de bijeenkomsten. De student met de rol van voorzitter leidt de bijeenkomst. Hij* bewaakt de agenda en zorgt voor een gelijke inbreng van alle studenten. Tijdens de eerste bijeenkomst van een week stimuleert en structureert hij de brainstormsessies. Tijdens de tweede bijeenkomst van een week leidt de voorzitter de discussie en feedback na afloop van de presentaties. De student met de rol van notulist noteert de afspraken en de uitkomsten van de brainstormsessie. Verder zijn er vier koppels die aan de opdrachten werken, elk koppel bestaat uit een opdrachtrapporteur en een partner. De opdrachtrapporteur is verantwoordelijk voor het uitwerken van de opdracht en het presenteren van de uitwerking tijdens de tweede bijeenkomst. De partner helpt bij het uitwerken van de opdracht. Tenslotte zijn er een aantal studenten die feedback geven aan de rapporteurs over de wijze waarop zij de uitwerkingen van de opdrachten hebben gepresenteerd. Gedurende het trimester rouleren de rollen: tijdens elke bijeenkomst vervult een student een andere rol.

De bijeenkomsten worden begeleid door een tutor. De tutor vervult vooral de rol van procesbegeleider. Dit houdt in dat hij op informele wijze met een kleine groep studenten moet communiceren, studenten zelf laat nadenken en op het juiste moment bijstuurt en stimuleert. ${ }^{2} \mathrm{Om}$ de leerprocessen te sturen en daarmee de leeruitkomsten te maximaliseren, dient de tutor een aantal functies te vervullen. Ten eerste zorgt een tutor voor bevordering van het affectieve klimaat. Hiermee wordt een omgeving bedoeld waarin de motivatie van studenten hoog is en de studenten een positief gevoel over hun eigen leren hebben. Om dit te bereiken interesseert en motiveert de tutor studenten voor de leerstof. Hij activeert studenten zich in te spannen en zelfvertrouwen te hebben. Daarnaast vervult de tutor een functie bij de regulatie van leerprocessen. Hierbij activeert de tutor kennis die studenten al hebben en stuurt zo nodig het leerproces bij. Met name het geven van feedback is hierbij belangrijk. ${ }^{3}$ Elke docent die als tutor gaat functioneren, wordt met behulp van een tweedaagse training voorbereid op deze rol.

\section{Tutorgroepbijeenkomsten zonder docent}

De opleidingen geneeskunde in Nederland hebben te maken met sterk toenemende studentenaantallen. Aangezien een groot gedeelte van het onderwijs bij de opleiding geneeskunde bij de FMW/RUG vanaf het eerste tot en met het vierde studiejaar in tutorgroepen plaatsvindt, zijn er steeds meer tutoren nodig. Dit leidt tot problemen bij het vinden van voldoende tutoren en tot een verhoging van de kosten. Het faculteitsbestuur heeft daarom opdracht gegeven mogelijkheden te zoeken om de docentinzet te beperken. Elk voorstel voor vermindering van docentinzet bleek echter een verandering van het onderwijsconcept en het onderwijsmateriaal met zich mee te brengen. ${ }^{4}$ De voor-

\footnotetext{
* Voor het leesgemak staat hier 'hij' geschreven. Daar waar 'hij' of 'zijn' geschreven staat kan ook 'zij' of 'haar' gelezen worden.
} 
stellen zorgden daardoor niet voor kostenbesparing. Om toch de docentinzet te verminderen, werd uiteindelijk besloten het onderwijsconcept intact te laten en in jaar 3 en 4 de tutor slechts bij één van de twee tutorgroepbijeenkomsten aanwezig te laten zijn, zonder het onderwijsmateriaal aan te passen. De studenten uit jaar 3 en jaar 4 hebben in de voorgaande jaren veel ervaring opgedaan met het werken in tutorgroepen en zijn goed bekend met de werkwijze en de rollen van tutorgroepbijeenkomsten.

Wanneer een tutor niet aanwezig is tijdens één van beide tutorgroepbijeenkomsten zullen de functies die een tutor normaliter vervult op een andere manier gerealiseerd moeten worden. Het motiveren, interesseren en activeren van studenten zou bijvoorbeeld moeten worden verwezenlijkt door de studieopdrachten. Een aantal functies van de tutor zullen echter moeilijk op te vangen zijn, zoals bijvoorbeeld het bijsturen van het leerproces, het reduceren van onzekerheden bij studenten en het geven van feedback. 5

In het algemeen zou het zelfstandig werken in groepjes een positieve werking kunnen hebben op de betrokkenheid en motivatie van de studenten. ${ }^{6-7}$ Binnen de onderwijsorganisatie bestonden echter verschillende opvattingen over welke bijeenkomst het beste zonder begeleiding zou kunnen plaatsvinden, de eerste dan wel de tweede bijeenkomst van de week. Hieronder worden de voor- en nadelen van beide opties geschetst.

\section{Eerste bijeenkomst zonder tutor}

Wanneer de tutor niet aanwezig is bij de eerste bijeenkomst betekent dit dat de brainstormsessie zonder begeleiding zal verlopen. Het voordeel hiervan kan zijn dat de studenten meer gaan participeren in de brainstorm. Uit onderzoek blijkt dat een tutor tussen de 50 en $60 \%$ van de dis- cussietijd aan het woord is. Ook neemt een tutor vaak het woord wanneer er een stilte valt. Wanneer de tutor niet aanwezig is tijdens de brainstormsessie kunnen studenten zelf meer aan het woord zijn en zullen ze zelf de stiltes moeten opvullen. ${ }^{7-8}$ Een tweede voordeel is dat de tutor bij de tweede bijeenkomst kan controleren of alle nodige kennis aan bod is geweest en feedback geven op de manier van presenteren van de opdrachtrapporteurs. Een nadeel van een eerste bijeenkomst zonder tutor is dat mogelijk niet alle voor de opdracht relevante onderwerpen aan bod komen of dat studenten informatie gaan zoeken die op dat moment niet van toepassing is. De tutor kan niet controleren of sturen met welke vragen de studenten aan de slag gaan, na afloop van de brainstormsessie.

\section{Tweede bijeenkomst zonder tutor}

Wanneer de tutor niet aanwezig is bij de tweede bijeenkomst betekent dit dat de opdrachtrapportages zonder begeleiding verlopen. Een voordeel hiervan kan zijn dat het presenteren van leerstof aan leeftijdgenoten in afwezigheid van een docent kan motiveren tot harder studeren. Daarbij komt dat het zelf doceren van kennis ervoor zorgt dat de docerende student de kennis beter onthoudt. ${ }^{9}$ Een tweede voordeel van deze situatie is de aanwezigheid van de tutor bij de eerste bijeenkomst. Hij kan de afspraken die na afloop van de brainstormsessie worden gemaakt eventueel bijsturen. Een nadeel is echter dat de tutor de rapporteurs bij de presentaties niet kan corrigeren en geen feedback kan geven.

Omdat er geen eenduidige voorkeur voor één van beide situaties bestond, werden in jaar 3 beide vormen toegepast. Gedurende het eerste trimester hebben studenten de eerste tutorgroepbijeenkomst van de week 
steeds zonder begeleiding doorlopen. Gedurende het tweede trimester van jaar 3 hebben deze studenten de tweede tutorgroepbijeenkomst van de week zonder begeleiding doorlopen. In dit onderzoek is deze studenten gevraagd naar hun voorkeur en de verschillen die zij ervaren tussen de conditie met een eerste bijeenkomst zonder begeleiding en de conditie met een tweede bijeenkomst zonder begeleiding.

\section{Methode}

\section{Proefpersonen en procedure}

Het onderzoek is uitgevoerd onder derdejaars studenten geneeskunde van de FMW/ RUG (N=272). Deze studenten hebben het eerste trimester van het cursusjaar 20022003 de eerste tutorgroepsbijeenkomsten zonder begeleiding doorlopen. Dat wil zeggen dat zij zelfstandig hebben gebrainstormd over vier opdrachten. Zij stuurden de tutor de uitkomsten van de brainstormsessie per mail en de tutor kon hier eventueel (per mail) feedback op geven. Tijdens het tweede trimester doorliepen deze studenten de tweede tutorgroepbijeenkomsten zonder begeleiding. De presentaties van de opdrachten werden zelfstandig gehouden. Wel ontving de tutor de schriftelijke uitwerkingen van de opdrachten en kon hij hier eventueel feedback op geven.

$\mathrm{Na}$ afloop van het tweede trimester is de studenten gevraagd een vragenlijst in te vullen. De gegevens zijn anoniem verwerkt.

\section{Instrument}

De vragenlijst bestaat uit 20 vragen, die op een 3-puntsschaal dienen te worden beantwoord (zie tabel 1). De vragen betreffen allereerst de kwaliteit van de taken/ agendapunten van de bijeenkomsten, namelijk de brainstorm, de opdrachtrapportages en de uitwerkingen van de opdrachten. In de tweede plaats wordt gevraagd naar de kwaliteit van de rollen van voorzitter en notulist en naar de samenwerking tussen rapporteur en partner. In de derde plaats wordt gevraagd naar de motivatie en inzet van studenten en de functie van de tutor. Op al deze aspecten wordt studenten gevraagd de situatie met een eerste bijeenkomst zonder begeleiding te vergelijken met de situatie van een tweede bijeenkomst zonder begeleiding. Verder wordt studenten gevraagd hun voorkeur te bepalen voor één van beide situaties. De vragenlijst wordt afgesloten met twee open vragen, waarbij studenten aan kunnen geven onder welke voorwaarden de eerste dan wel de tweede bijeenkomst zonder begeleiding toch effectief doorlopen kan worden.

\section{Resultaten}

De vragenlijst is ingevuld door 241 studenten $(88.6 \%)$. In tabel 1 is te zien dat volgens de meeste studenten de verschillende rollen in beide situaties even goed werden uitgevoerd. Opvallend is dat bijna $40 \%$ van de studenten de kwaliteit van de brainstormsessie als minder beoordeelde wanneer deze zonder begeleiding plaatsvond. Volgens 33\% van de studenten was deze kwaliteit in beide situaties gelijk. De kwaliteit van de presentaties was volgens $48.3 \%$ van de studenten in beide situaties hetzelfde en $35 \%$ vond deze kwaliteit hoger wanneer de presentaties onder begeleiding van een tutor plaatsvonden.

De voorbereiding van de studieopdrachten kostte in beide situaties evenveel tijd (77.9\%). Ook de motivatie voor de tutorgroepbijeenkomsten verschilde volgens de meeste studenten niet $(64.3 \%)$. Voor beide situaties gaf ongeveer $65 \%$ aan dat elke bijeenkomst zonder begeleiding doorging en $30 \%$ dat deze bijeenkomsten soms niet doorgingen. Het overslaan van een bijeenkomst zonder begeleiding en het zelf afwezig zijn bij de bijeenkomst zonder be- 
Tabel 1. Percentage studenten dat een bepaald antwoord heeft gegeven. In de meeste gevallen wordt gevraagd de situatie met een eerste bijeenkomst zonde tutor te vergelijken met de situatie met een tweede bijeenkomst zonder tutor. De hoogste percentages staan vetgedrukt.

\begin{tabular}{|c|c|c|c|}
\hline \multirow[t]{2}{*}{ Items $(\mathrm{N})$} & \multicolumn{3}{|c|}{ Percentage studenten } \\
\hline & $\begin{array}{l}\text { Hoger bij 1e } \\
\text { bijeenkomst } \\
\text { zonder tutor }\end{array}$ & $\begin{array}{l}\text { Gelijk in } \\
\text { beide } \\
\text { situaties }\end{array}$ & $\begin{array}{l}\text { Lager bij 1e } \\
\text { bijeenkomst } \\
\text { zonder tutor }\end{array}$ \\
\hline 1. Kwaliteit van presentaties (234) & 35.0 & 48.3 & 16.7 \\
\hline 2. Kwaliteit van uitwerkingen (234) & 24.8 & 62.4 & 12.8 \\
\hline 3. Kwaliteit samenwerking rapporteur/ partner (234) & 3.8 & 94.0 & 2.1 \\
\hline 4. Kwaliteit van functioneren voorzitter (231) & 14.7 & 77.5 & 7.8 \\
\hline 5. Kwaliteit van functioneren van notulist (233) & 11.6 & 81.5 & 6.9 \\
\hline 6. Kwaliteit van brainstorm (233) & 26.2 & 33.9 & 39.9 \\
\hline 7. Mijn motivatie voor de tutorbijeenkomsten (233) & 21.9 & 61.8 & 16.3 \\
\hline \multirow[t]{2}{*}{ 8. Gemiddelde aantal absenties (235) } & 16.6 & 55.7 & 27.7 \\
\hline & $\begin{array}{l}\text { Meer bij 1e } \\
\text { bijeenkomst } \\
\text { zonder tutor } \\
\end{array}$ & $\begin{array}{l}\text { Even veel } \\
\text { in beide } \\
\text { situaties }\end{array}$ & $\begin{array}{l}\text { Minder bij 1e } \\
\text { bijeenkomst } \\
\text { zonder tutor }\end{array}$ \\
\hline 9. Voorbereidingstijd studieopdrachten (235) & 16.6 & 77.9 & 5.5 \\
\hline 10. Motivatie overnemen van taken tutor (230) & 18.7 & 64.3 & 17.0 \\
\hline 11. Begeleiding op inhoud gericht (231) & 26.8 & 56.3 & 16.9 \\
\hline \multirow[t]{2}{*}{ 12. Begeleiding op groepsproces gericht (232) } & 10.8 & 68.1 & 21.1 \\
\hline & Vaak & Soms & Nooit \\
\hline 13. Overslaan onbegeleide bijeenkomst in 3.1 (235) & 2.6 & 31.9 & 65.5 \\
\hline \multirow[t]{2}{*}{ 14. Overslaan onbegeleide bijeenkomst in 3.2 (235) } & 6.0 & 30.2 & 63.8 \\
\hline & $\begin{array}{l}\text { Vaker bij 1e } \\
\text { bijeenkomst } \\
\text { zonder tutor } \\
\end{array}$ & $\begin{array}{l}\text { Even vaak } \\
\text { in beide } \\
\text { situaties }\end{array}$ & $\begin{array}{l}\text { Minder bij 1e } \\
\text { bijeenkomst } \\
\text { zonder tutor }\end{array}$ \\
\hline 15. Overslaan onbegeleide bijeenkomst (232) & 14.2 & 64.7 & 21.1 \\
\hline \multirow[t]{2}{*}{ 16. Afwezigheid bij onbegeleide bijeenkomst (231) } & 6.1 & 74.9 & 19.0 \\
\hline & $\begin{array}{l}\text { Beter bij 1e } \\
\text { bijeenkomst } \\
\text { zonder tutor } \\
\end{array}$ & $\begin{array}{l}\text { Even goed } \\
\text { in beide } \\
\text { situaties }\end{array}$ & $\begin{array}{l}\text { Slechter bij 1e } \\
\text { bijeenkomst } \\
\text { zonder tutor }\end{array}$ \\
\hline \multirow[t]{2}{*}{ 17. Opvang afwezigheid tutor (232) } & 30.6 & 44.0 & 25.4 \\
\hline & Heel erg & Enigszins & Niet \\
\hline \multirow[t]{2}{*}{ 18. Inzet van studenten bepalend voor goed verloop (234) } & 75.6 & 23.5 & .9 \\
\hline & Mee eens & Mee oneens & Geen mening \\
\hline \multirow[t]{2}{*}{ 19. Tutor gaf goede feedback (234) } & 51.3 & 32.1 & 16.7 \\
\hline & 1e onbegeleid & 2e onbegeleid & Maakt niet uit \\
\hline 20. Voorkeur (233) & 51.1 & 41.6 & 7.3 \\
\hline
\end{tabular}


geleiding kwam in beide situaties even vaak voor.

Voor een goed verloop van een bijeenkomst zonder begeleiding wordt de inzet van studenten als erg bepalend ervaren. Over de vraag welke bijeenkomst het beste zonder begeleiding plaats kan vinden, zijn de studenten verdeeld. De helft van de studenten heeft het liefst begeleiding bij de tweede bijeenkomst en $40 \%$ bij de eerste bijeenkomst. De rest van de studenten heeft geen voorkeur voor één van beide situaties.

Op de vragen naar voorwaarden voor een goed verloop van de bijeenkomst zonder begeleiding, kwamen een aantal onderwerpen naar voren. In tabel 2 is te zien dat bij een eerste bijeenkomst zonder begeleiding met name de motivatie en aanwezigheid van studenten en het beschikbaar zijn van richtlijnen bij de opdrachten (een handleiding) door de studenten van belang worden geacht. Voor een goed verloop van een tweede bijeenkomst zonder begeleiding ligt de nadruk vooral op het feedback krijgen op de uitwerkingen van de studieopdrachten en op controle op aanwezigheid. Ook hier speelt de motivatie en aanwezigheid van studenten een belangrijke rol.

\section{Discussie en conclusies}

Dit onderzoek is gericht op de ervaringen van studenten met tutorgroepen, waarbij studenten de eerste dan wel de tweede bijeenkomst zonder begeleiding van een tutor doorliepen. Uit de resultaten blijkt dat onder de studenten geen duidelijke voorkeur voor één van beide situaties bestaat. Wellicht zien studenten de verschillende voor- en nadelen van beide situaties, waardoor geen van beide een duidelijke voorkeur krijgt.

De belangrijkste bevinding is dat een groot deel van de studenten vindt dat de onderdelen zonder begeleiding (het brainstormen dan wel de presentaties) slechter werden uitgevoerd dan toen zij wel onder begeleiding plaatsvonden. Een eerste mogelijke verklaring hiervoor is dat de voorbereiding van studenten op deze nieuwe situatie wellicht niet voldoende is geweest. Hoewel de studenten gedurende twee studiejaren in tutorgroepen hebben gewerkt, waarbij ze tweemaal per week bijeenkwamen, volgens een vaste agenda werkten en de verschillende rollen regelmatig hebben vervuld, is deze voorbereiding blijkbaar te beperkt om een bijeenkomst goed zonder tutor te kunnen doorlopen. Uit onderzoek blijkt dat tutor-

Tabel 2. Aantal studenten dat een bepaald antwoord geeft op de vraag naar voorwaarden waaronder een bijeenkomst zonder tutor goed zou kunnen verlopen.

\begin{tabular}{lcc}
\hline Onderwerpen & $\begin{array}{c}\text { Goed verlopen van } \\
\text { een eerste bijeenkomst } \\
\text { zonder tutor }\end{array}$ & $\begin{array}{c}\text { Goed verlopen van } \\
\text { een tweede bijeenkomst } \\
\text { zonder tutor }\end{array}$ \\
\hline Richtlijnen/ handleiding & 25 & 10 \\
Bijeenkomst na eerste college & 11 & - \\
Motivatie en aanwezigheid studenten & 62 & 39 \\
Kwaliteit van de opdrachten & 18 & - \\
Feedback en controle & 12 & 60 \\
Invloed van de andere bijeenkomst & - & 9 \\
Kan niet zonder begeleiding & 3 & 13 \\
Gaat al goed zonder begeleiding & 6 & 5 \\
Anders & 5 & 3 \\
\hline
\end{tabular}


groepen zonder tutor andere problemen ervaren dan tutorgroepen waar wel een tutor aanwezig is. ${ }^{10}$ Deze problemen zijn nieuw voor de studenten. Volgens Woods et al. is het belangrijk studenten hier goed op voor te bereiden. ${ }^{7} 10$ Problemen die tutorgroepen zonder tutor kunnen ervaren, zijn bijvoorbeeld de frustratie dat sommige leden hun taken niet of onvoldoende uitvoeren en meeliften met de anderen uit de groep. Ook de afwezigheid van studenten kan een probleem zijn waar tutorgroepen zonder tutor mee te maken krijgen. Dit wordt door de studenten van de FMW/RUG ook aangegeven. Zij vragen nadrukkelijk om controle, met name wanneer de tweede bijeenkomst zonder tutor verloopt. Tijdens de tweede bijeenkomst wordt de kennis die de studenten opgedaan hebben met elkaar gedeeld. Als er een student dan niet aanwezig is, kan dit nadelige consequenties hebben voor de overige leden van de groep, wat de grotere vraag om controle zou kunnen verklaren. ${ }^{10}$

Een verklaring voor de verminderde kwaliteit van de brainstormsessie kan zijn dat studenten afhankelijk zijn geworden van de aanwezigheid, met name de inbreng, van de tutor. Zoals in de inleiding is besproken, blijkt een tutor een groot gedeelte van de discussietijd aan het woord te zijn en vaak de stiltes op te vullen. Webb geeft aan dat in de beginperiode van het werken met discussiebijeenkomsten zonder tutor het aantal stiltes zal toenemen. Op langere termijn zullen studenten leren stiltes zelf op te vullen en hier geen tutor meer voor nodig hebben. ${ }^{8}$ Wellicht was de huidige onderwijseenheid hiervoor te kort.

Een tweede verklaring voor de verminderde kwaliteit van de brainstormsessies kan zijn dat niet alle leerdoelen worden bereikt wanneer er geen tutor aanwezig is. Uit onderzoek is gebleken dat dit bij brainstormsessies waar geen tutor aanwezig is vaak voorkomt. ${ }^{11}$ De vraag van studenten om duidelijkere richtlijnen danwel een handleiding met de leerdoelen sluit hier goed bij aan. Dit vergt echter aanpassing van het onderwijsmateriaal en dus extra investeringskosten. Duek en Wilkerson adviseren geen tutorgroepen zonder begeleiding te hanteren wanneer leerdoelen alleen in de tutorgroepen worden behandeld en verder in het curriculum niet terugkomen. ${ }^{11}$ In Groningen wordt aan het eind van de week in het responsiecollege en in het magistraal college ook aandacht aan de leerdoelen besteed.

Een verklaring voor de verminderde kwaliteit van de opdrachtrapportages bij tutorgroepen zonder tutor kan zijn dat studenten hun voorbereiding op de rapportages zonder begeleiding van een tutor niet hebben aangepast ten opzichte van de voorgaande jaren. De voorbereidingstijd is namelijk niet langer wanneer de opdrachtrapportages zonder begeleiding plaatsvinden. Op basis van de literatuur zou men dit echter wel mogen verwachten. ${ }^{9}$ Verder wordt er geen feedback gegeven door de tutor, iets wat moeilijk is op te vangen door studenten, maar dat wel belangrijk is voor het bevorderen van het leerproces. ${ }^{3-4}$

Op basis van deze gegevens is geen duidelijke voorkeur voor één van beide situaties aan te geven. Het lijkt zelfs helemaal niet verstandig om te gaan werken met tutorgroepbijeenkomsten zonder begeleiding, tenminste niet zonder compenserende maatregelen. Het laten vervallen van de tutorbegeleiding zonder aanpassing van het onderwijsconcept en het onderwijsmateriaal heeft volgens studenten een negatief effect op de kwaliteit van verschillende onderdelen. Het werken in slechts gedeeltelijk begeleide groepen kan positieve effecten hebben wanneer studenten en docenten hier goed op worden voorbereid. ${ }^{7-9}$ Aanpassing van het onder- 
wijsconcept en het onderwijsmateriaal is hierbij belangrijk, zodat de functies die normaalgesproken door een docent zouden worden vervuld goed overgenomen worden. ${ }^{3-4}$

Een kanttekening bij dit onderzoek is dat het op reactieniveau plaatsvond. De mening van de studenten over de kwaliteit van de verschillende onderdelen kan afwijken van de daadwerkelijke kwaliteit. Een tweede kanttekening is dat de condities in twee verschillende trimesters plaatsvonden. Deze trimesters verschilden inhoudelijk van elkaar. Daarbij komt dat de trimesters na elkaar plaatsvonden. Het kan zijn dat het werken met een eerste bijeenkomst zonder tutor van invloed is geweest op het werken met een tweede bijeenkomst zonder tutor.

In vervolgonderzoek zouden beide condities binnen één trimester moeten plaatsvinden. De ene helft van de tutorgroepen zou dan de eerste bijeenkomst zonder tutor moeten uitvoeren en de andere helft de andere. Ideaal zou zijn om nog een derde conditie hieraan toe te voegen, waarin beide bijeenkomsten onder begeleiding van een tutor zouden plaatsvinden. Vervolgonderzoek zou zich kunnen richten op de invloed van tutorgroepen zonder begeleiding op de leerresultaten. Bij het vierde jaar van de FMW/RUG wordt op dit moment geprobeerd beter zicht te krijgen op de invloed van het werken in slechts gedeeltelijk begeleide tutorgroepbijeenkomsten op studieprestaties. $\mathrm{Bij}$ het derde jaar is op basis van de uitkomsten van dit onderzoek besloten beide tutorgroepbijeenkomsten van een week weer onder tutorbegeleiding plaats te laten vinden.

\section{Literatuur}

1. Maudsley G, Strivens J. "Science", "critical thinking" and "competence" for tomorrow's doctors. A review of terms and concepts. Med Educ 2000;34:53-60.
2. Harden RM, Crosby J. AMEE Guide No. 20: The good teacher is more than a lecturer - The twelve roles of the teacher. Med Teach 2000;22(4):334-47.

3. Vermunt JDHM. Leerstijlen en sturen van leerprocessen in het hoger onderwijs. Naar procesgerichte instructie in zelfstandig denken. Amsterdam/ Lisse: Swets \& Zeitlinger; 1992.

4. Wouda J. Revisie weekconcept trimester 3.1-4.1. Groningen: Onderwijsinstituut Faculteit der Medische Wetenschappen, Rijksuniversiteit Groningen; 2000.

5. Schönrock-Adema J. De ontwikkeling en evaluatie van een zelfinstructieprogramma voor een training in basisgespreksvaardigheden [dissertatie]. Groningen: Rijksuniversiteit Groningen; 2002.

6. Light RJ. The Harvard assessment Seminars. Explorations with students and faculty about teaching, learning and student life. First report. Cambridge, Massachusetts: Harvard University; 1990.

7. Powell JP. Small group teaching methodes in higher education. Educational Research 1974;16:16371.

8. Webb G. The tutorial method. Learning strategies and student participation in tutorials: some problems and some suggested solutions. Programmed Learning and Educational Technology 1983;20(2):117-21.

9. Allen VL, Feldman RS. Studies on the role of the teacher. In: Allen VL, editor. Childeren as Teacher. New York: Academic Press; 1976.

10. Woods DR, Hall FL, Eyles CH, Hrymak AN, Duncan-Hewitt WC. Tutored versus tutorless groups in problems-based learning. Am J Pharm Educ 1996;60(3):231-8.

11. Duek JE, Wilkerson L. Learning issues identified by students in tutorless problem-based tutorials. U.S.: California (Abstract ERIC Database);1995.

\section{De auteurs:}

Mw. drs. M. Penninga is werkzaam bij de afdeling Onderwijsontwikkeling en Kwaliteitszorg van het Onderwijsinstituut.

Mw. dr. J. Schönrock-Adema is werkzaam bij de afdeling Onderwijsontwikkeling en Kwaliteitszorg van het Onderwijsinstituut.

Mw. dr. J. Cohen-Schotanus is hoofd van de afdeling Onderwijsontwikkeling en Kwaliteitszorg van het Onderwijsinstituut.

Allen zijn verbonden aan de Faculteit der Medische Wetenschappen van de Rijksuniversiteit Groningen.

\section{Correspondentieadres:}

Mw. drs. M. Penninga, Onderwijsinstituut, Afdeling Onderwijsontwikkeling en Kwaliteitszorg, Faculteit der Medische Wetenschappen, Rijksuniversiteit Groningen, A. Deusinglaan 1, 9713 AV Groningen, tel: 050-3638261, fax:050-3633865, m.penninga@med.rug.nl. 


\section{Summary}

Introduction: Students at the Faculty of Medicine in Groningen, the Netherlands, meet twice a week to solve medical problems. In the first meeting they brainstorm about the problems, then they search for answers, which they report in the second meeting. The growing numbers of students and a shortage of tutors prompted the decision to hold one meeting without a tutor present. Because no consensus was reached about which meeting should be unsupervised, we sought students' opinions on this.

Method: We conducted a study among 272 students. During the first trimester and the second trimester, supervision was limited to the first meetings and the second meetings, respectively. After these two trimesters, 241 students (88.6\%) completed a questionnaire consisting of 20 questions in which students were asked to indicate their appreciation of the two conditions on a three-point scale.

Results: Supervision of the second meeting was preferred by half of the students and $40 \%$ preferred supervised first meetings. Almost $40 \%$ felt that the quality of brainstorm sessions suffered when there was no supervision. The quality of reporting was rated about the same in both conditions by $48.3 \%$ of the students and $35 \%$ rated the quality of the sessions without tutor as inferior.

Discussion and conclusions: A large percentage of the students indicated that the quality of sessions suffered when there was no supervision. No clear preference was found for either of the conditions. Further studies should examine the effects of tutorless group meetings on study results. (Penninga M, Schönrock-Adema J, Cohen-Schotanus J. Tutorless tutorials: what do the students think? Dutch Journal of Medical Education 2004;23(5):211-219.) 